\title{
\#DryLabs20: A New Global Collaborative Network to Consider and Address the Challenges of Laboratory Teaching with the challenges of COVID-19.
}

Craig D. Campbell ${ }^{1}$, Ben Challen ${ }^{1}$, Kristy L. Turner ${ }^{2,3}$ and Malcolm I. Stewart ${ }^{1 *}$

1. Department of Chemistry, University of Oxford, Chemistry Teaching Laboratory, South Parks Road, Oxford, OX1 3PS

2. Department of Chemistry, University of Manchester, Oxford Road, Manchester, M13 9PL

3. Bolton School Boys' Division, Chorley New Rd, Bolton, BL1 4PA

\section{ABSTRACT}

Since the sudden emergence of COVID-19 global pandemic, all educational institutions have looked to move resources and delivery online. Some institutions had already embraced delivering instruction in this way, however, broader adaptation to this teaching style is new to many educators. While the teaching of theoretical concepts is more easily transferred to a blended learning environment, the teaching of practical chemistry poses significant challenges, yet it is crucial to the chemist's identity.

Here we describe the establishment of a new, international, network to consider how practical chemistry can be taught outside of the traditional laboratory environment and invite readers of this special edition of the journal to join. Meeting fortnightly and maintaining links through a shared networked drive between meetings, the network has been accessed by over 100 delegates in the UK, mainland Europe, North America and Australasia. The traditional siloes of chemistry have not defined the discussions, which have instead focused on logistical aspects such as social distancing and the pastoral role of the laboratory environment. Initial evaluation shows the network is valued by its members and is making progress towards its aims.

GRAPHICAL ABSTRACT 


\section{\#DryLabs20}

25

\section{KEYWORDS}

First-Year Undergraduate / General; Second-Year Undergraduate; Upper-Division Undergraduate;

Graduate Education / Research; Curriculum; Laboratory Instruction; Distance Learning / Self

Instruction

\section{INTRODUCTION}

Since the sudden emergence of COVID-19 global pandemic, all educational institutions have looked to move resources and delivery online. Teaching of theoretical concepts, usually undertaken in lectures and tutorials, are most easily transferable to the online environment, especially in institutions that have already embraced e-learning. Across the world, education institutions from primary schools to universities have embraced video conferencing tools such as Zoom, Microsoft Teams, Blackboard Collaborate and Skype to deliver synchronous teaching of theory. ${ }^{1}$ However, significant challenges remain in planning and implementing for practical chemistry laboratory classes in the blended learning environment. A straightforward solution to these challenges would be the postponement of laboratory teaching until a more 'normal' chemistry education environment can be provided. This option, however, is not possible within the current approval/accreditation frameworks; the two major approvers/accreditors of chemistry degrees are the American Chemical Society (ACS) Committee on Professional Training and the Royal Society of Chemistry (RSC). The ACS requires bachelor degrees to have 400 hours of laboratory experience beyond introductory chemistry, ${ }^{2 a}$ and the RSC requires between

requirement for an undergraduate research project. ${ }^{3 a}$ In saying this, both the $\mathrm{ACS}^{2 \mathrm{~b}}$ and $\mathrm{RSC}^{3 \mathrm{~b}}$ have adjusted their specifications in June 2020 to take the COVID-19 pandemic into account. 
Removing laboratory classes, even in the short term, would pose significant difficulties in achieving the accreditation criteria. Additionally, such a proposal would be in direct opposition to the identity of chemists. ${ }^{4}$

There is an abundance of literature on practical chemistry, with the vast majority relying on a traditional laboratory environment in either schools or universities. In this there is an assumed level of space, apparatus and teaching support. The model for undergraduate chemistry education in the UK and Ireland usually involves students attending a laboratory class at least once per week during the semester. This normal environment may not be possible in the autumn semester 2020 as planned social distancing guidelines may limit student access, restricting the level of laboratory occupancy. Furthermore, many HEIs have significant numbers of international students who may be subject to travel restrictions, or may be nervous about moving abroad for study during a pandemic.

In order to overcome some of these issues, it is likely that university chemistry departments will need to design non-laboratory based practical experiences, or 'drylabs'. The term 'drylab' may be most familiar to analytical chemists working in chromatography, where international collaboration resulted in the development of simulation software called DryLab ${ }^{\circledR}$ in the 1980 s. ${ }^{5}$ Here, we use the term more widely to describe an activity which meets the aims of laboratory teaching, but takes place in a non-laboratory environment and without the associated apparatus and personnel.

Drylabs as a learning technique is not new. The use of computer simulations as a way to extend a student's experience beyond what is feasible or even possible in the laboratory at a given level has been of interest since the 1970 s. ${ }^{6}$. They began to be integrated into the more traditional hands-on areas like organic chemistry in the $1980 \mathrm{~s}^{7}$ and researchers began to consider the effectiveness of learning in a hands-on and computer simulated environments later in that decade. ${ }^{8}$ More recently, computer simulations have become commonplace as pre-laboratory activities, ${ }^{9}$ but they have not replaced the standard laboratory class which remains hands-on. Computer simulations are not the only possible drylab experience; any activity that meets the objectives of a laboratory course ${ }^{10}$ could be considered as a drylab activity. These might include planning and risk assessment exercises, report writing and data analysis. 


\section{THE CASE FOR COLLABORATION}

Many institutions will have some drylabs within their existing laboratory program. For some highly specialized institutions, such as the Open University in Milton Keynes, UK, the majority of their practical work is conducted through a drylab environment. The proverb goes that 'many hands make light work,' and it was hoped that the establishment of this new network would help lessen the load for academics faced with adapting their laboratory programs during COVID-19 restrictions. HE institutions are normally considered in competition with one another, both for research funding and for students, as tuitions fees provide a source of funding. Collaboration, therefore, may seem unnatural, and there is little in the literature describing collaboration between HE institutions. ${ }^{11}$ Collaboration provides a mechanism for dealing with people which respects and highlights the abilities and contributions of individual group members. In successful collaboration, there is a sharing of authority and acceptance of responsibility among group members for the groups' actions. ${ }^{12}$

There are a number of networks facilitating discussion between institutions, with learned societies including the ACS and RSC being key facilitators. These networks tend to center around the sharing of ideas at meetings and conferences. True collaboration, the sharing of workload towards a shared objective, is much less common. Notable examples of such successful collaborations are the IONiC-VIPEr ${ }^{13}$ and the POGIL projects. ${ }^{14}$ Subject-focused collaborative networks have been developed, though these tend to be localized within cities, ${ }^{15}$ or regionally. ${ }^{16}$ There are also subject-focused networks that take advantage of the online space to facilitate collaboration internationally, however, progress is slow as the network grows organically. ${ }^{17}$ The literature is rich with examples describing the benefits of inter-disciplinary and cross-disciplinary education collaboration for undergraduate student projects and courses ${ }^{18}$ and collaboration between higher education and high schools. ${ }^{19}$ Thus, developing a larger, more diverse, inter- and cross-disciplinary network would serve as a powerful vehicle for innovation and development of ideas.

\section{THE DRYLABS20 NETWORK}

To address the potential issues of delivering a practical program in the COVID-19 era, the authors from the University of Oxford established a new online network focused on resolving this task, named \#DryLabs20. This was initiated by contacting educators in the UK through existing network 
channels, and advertising the network more generally via Twitter. The University of Oxford authors then have organized the meetings.

At the time of submission (July 2020), there have been seven online meetings recorded through the Zoom video communication platform. Invitations to collaborate were advertised through established networks, including those facilitated by the RSC as well as by social media, primarily Twitter. The live meetings have generally been attended by around 100 participants, principally from the UK (all four nations) but also delegates from the US, Europe and Australia. Most attendees are academics and instructors in higher education who have roles aligned with laboratory work, but there is also interest and involvement from laboratory technicians and high school teachers.

At its inception, the wide-ranging and ambitious aims of this network were to

(1) Bring chemistry educators together and develop a broad sense of community

(2) Create a repository of fully developed, implementable materials from the community

(3) Forge new collaboration for innovation and development of new ideas

(4) Tackle the challenges of teaching in the current (COVID19) climate and beyond

(5) Understand the full impact, purpose and value of laboratory-based teaching

The format was designed to mirror the structure found in face-to-face conferences and professional meetings, beginning with housekeeping and introductions followed by presentations, then breaks for networking and discussion. In accordance with UK GDPR requirements, participants were required to register to a mailing list, which sent out details of upcoming events. The main room presentations and discussions have been recorded and made accessible to all network members. The forum is still highly active, and welcomes all interest from educators in the field worldwide.

The presentations offered have grown organically as the network has established and have included contributions from academics in HEIs, specialists in online learning, educators working at the interface between high school and higher education, suppliers of virtual laboratory simulations, and learned societies. As the Universities of Oxford and York had a number of weeks of teaching remaining when national shutdowns were implemented, they have presented their experiences of delivering a laboratory curriculum through blended learning during the COVID-19 lockdown period. This initial experience of online delivery has been vital in framing further discussions as other institutions plan for 
delivery in the autumn. Given the importance to educators of being able to meet accreditation requirements, the RSC presented their initial thoughts on how the accreditation framework could be adapted, so students suffer no detriment, whilst ensuring the importance of the laboratory experience to undergraduate chemistry education is maintained. Ideas for new ventures have been presented, including development of coding skills, the use of personal action cameras for filming techniques in the laboratory, and the potential of home chemistry kits. Presentations were also delivered on planning for social distancing in laboratory buildings and prior knowledge of students transferring to the first year of undergraduate study. Between sessions, members of the network are invited to contribute resources to a shared drive.

\section{INSIGHTS FROM BREAKOUT ROOMS}

Breakout rooms are sub-rooms within a central meeting or training session whether that is in a face-to-face or online meeting. They are useful for splitting a large group into smaller groups with common interests so they can talk or collaborate more easily. This has proved to be the case for this network, with one participant noting, "breakout sessions provide opportunity for everyone to contribute." The DryLabs20 breakout rooms were initially designed around the main branches of chemistry, (physical, organic, inorganic and analytical), however it was quickly apparent these traditional siloes were not sufficient for the needs of the attendees. Figure 1 shows how the breakout rooms have changed according to the needs of the network.

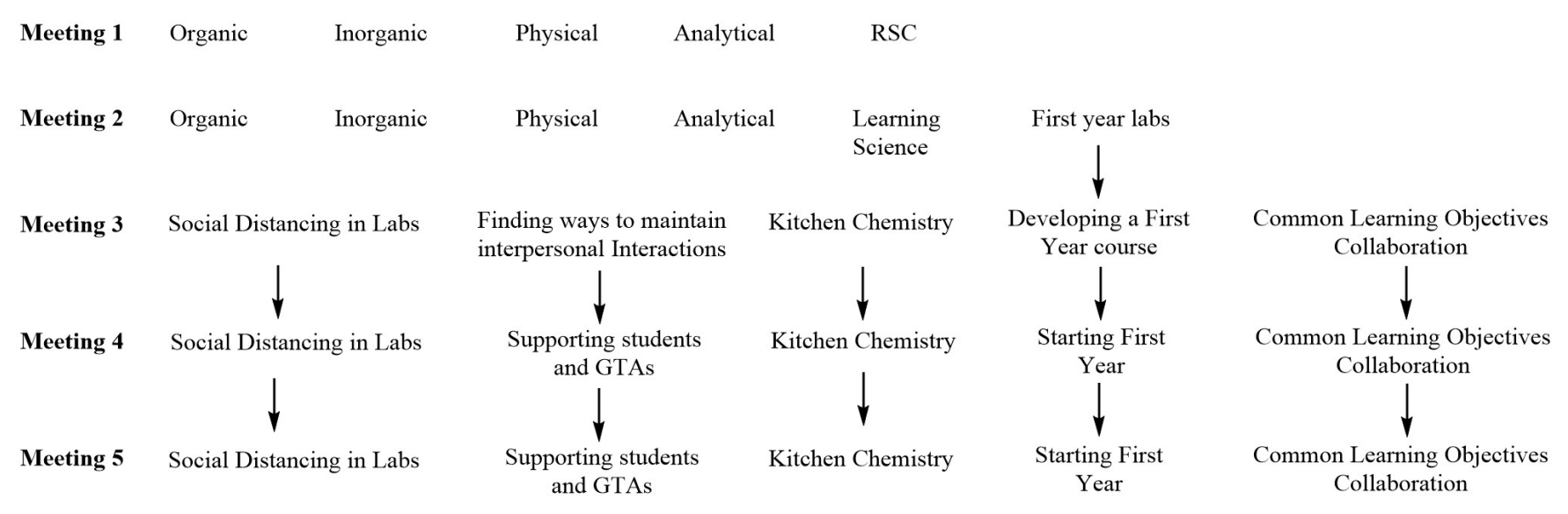


As the discussions have evolved, there have been key insights into the magnitude of the challenges facing educators in moving laboratory teaching to a blended learning environment.

Discussions brought up potential issues with student engagement and motivation, and so the theme of supporting students and graduate teaching assistants emerged. Network members highlight that the teaching labs are "more than just the place where students perform practical chemistry." Motivation comes from an interplay between personality, social cognition, developmental history and social relationships. ${ }^{20}$ Many of the interactions and friendships that develop within a cohort are forged in the laboratory environment, and these feed into student motivation, success and belonging. ${ }^{21}$ Research into the role of social networks in student success has shown social integration differed descriptively and statistically between successful first year engineering students and those who dropped out or failed first year. ${ }^{22}$ This is confirmed by a number of other studies, students who are socially isolated are less academically successful and at a higher risk of dropping out. ${ }^{23,24}$

This pastoral side of the laboratory environment has resonated strongly in the sessions and can be seen in the development of the breakout rooms focusing on the experience of $1^{\text {st }}$ year students, supporting students, and graduate teaching assistants. Network members feel that strong relationships are forged with the teaching laboratory staff, meaning laboratory instructors are able informally to monitor the welfare of the students. Online delivery of practical work would present a real problem, especially for incoming students, who, unlike previous cohorts of students, will not be able to develop these relationships readily. The laboratory environment is a challenging one for transition to undergraduate study, ${ }^{25}$ and the additional challenges posed by a blended learning environment may hinder this transition. Moving online, a significant shift in responsibility is placed on the student, where they must be pro-active in seeking help - this could prove highly challenging, and it could become very easy for a student to be overlooked if regular contact is not maintained.

Breakout room discussions also frequently featured concerns and speculation about the consequences of new governmental recommendations on infrastructure and logistics in light of COVID-19, including social distancing, and remote delivery. The development of the network's community spirit, being 'in it together', has helped mitigate the sense of a lack of control about these 
issues. Breakout rooms specifically discussing social distancing in labs have been a feature of the three latest meetings.

\section{NETWORKS BEYOND CHEMISTRY}

The creation of the DryLabs20 chemistry network has acted as a catalyst for the creation of at least three spin-off groups so far, namely: DryLabsRealScience (Biology), the PHYSICS-LTHE group (Physics) and DryLabsDownUnder (the Australasian version of the Chemistry group). Communication between the various groups is proceeding, and we hope this collective approach will prove a fertile ground for cross-disciplinary developments, reflective of the nature of current research.

\section{MEASURING SUCCESS}

With any intervention, evaluation is key to ensuring success and in maintaining relevance. There are many frameworks for evaluating the value of collaboration, ${ }^{26}$ however, the nature of establishing a new collaborative network during a global pandemic has meant these were unable to be implemented. Instead, the initial thoughts of attendees was sought using a short survey $(n=25)$. The survey instrument is available (see Electronic Supporting Information).

The main vehicle for attendees finding out about the planned sessions was by word of mouth, suggesting we need to work harder to use other established networks to reach out to educators who may benefit from this new collaboration. The attendees indicated that their main motivation to joining the network was a need to engage with like-minded people who were all trying to solve the same problem: how to teach practical chemistry online. This confirms that, as a community, we have not yet embraced non-traditional methods of laboratory teaching.

Most respondents (15) were pleased with what has been achieved by the network so far, with the remaining respondents (10) somewhat happy. The main benefit of the meetings has been feeling part of a team, finding out what colleagues in other institutions are doing, and meeting new people. At the time of preparing this manuscript there have been no collaborative outputs however we are optimistic that this will change as the network matures. It has been clearly demonstrated in the feedback that participants feel that this initiative has relevance moving beyond the current COVID-19 crisis. Of the 25 respondents, 19 people intend to attend every session they practicably can, and the remaining respondents indicated they would consider still attending after the current pandemic subsides. 
Returning to the aims of the network at its inception, it is clear that objectives relating to the building of community (objectives 1 and 3) have been mostly met. Attendees commented that the network is "very friendly, to both established chemistry educators and new members," with "Free discussion, sharing of experiences, making connections with larger departments". The discussions that have taken place have focused everyone's thoughts as to the purpose of laboratory education - an emerging theme within current education research. ${ }^{10}$ Whether the network allows members to tackle the challenges of teaching as the COVID-19 situation develops (objective 4) is yet to be seen.

One objective where progress has been slower is in the establishment of a repository of dry lab activities (objective 2). Given the constantly changing situation regarding the COVID-19 pandemic and its influence on educational establishments, educators have rightly been focusing on their own local priorities, including the completion of the 2019-20 cycle of teaching and assessment. We hope to use upcoming meetings to prioritize this objective, and hopefully lessen the workload for network members whose summer priorities will involve redesigning their laboratory courses. In recent weeks, encouraging signs of progress have been seen, with discussions beginning between network members and beyond.

Research is in progress to assess the full value and impact of the network, and will be reported in due course. We are currently in the process of developing a more widely accessible online resource to access shared/developed materials, and these materials may be disseminated through journal publication and via social media platforms (\#DryLabs20).

\section{CONCLUSION AND OUTLOOK}

A new network for the consideration of dry labs has been established using collaborative working tools. This has been of great benefit in building a community of like-minded educators around the world. The challenges presented by the disparate needs and timelines of individual institutions has hindered progress towards tangible outcomes, but we are optimistic this can be achieved as the network matures. We invite readers of this special edition of the journal who share our vision to join the network. 


\section{ASSOCIATED CONTENT}

Supporting Information

The Supporting Information is available on the ACS Publications website at DOI:

10.1021/acs.jchemed.XXXXXXX. [ACS will fill this in.]

Survey instrument

DryLabs20 Feedback (XLSX)

\section{AUTHOR INFORMATION}

Corresponding Author

*E-mail: Malcolm.Stewart@,chem.ox.ac.uk

\section{ACKNOWLEDGMENTS}

The authors would like to acknowledge the contributions of the members of the DryLabs20 network in making such progress towards our shared aims and the support of the Department of Chemistry at the University of Oxford.

1. https://www.theverge.com/2020/4/29/21240942/google-meet-free-zoom-response-microsoftteams-features (accessed Jun 2020)

2. (a) Undergraduate Professional Education in Chemistry: ACS Guidelines and Evaluation Procedures for Bachelor's Degree Programs; American Chemical Society: Washington, DC, 2015. (b) https://www.acs.org/content/acs/en/about/governance/committees/training.html Accessed July 2020.

3. (a) Accreditation of Degree Programmes; Royal Society of Chemistry: Cambridge, 2015. (b) https://www.rsc.org/membership-and-community/degree-accreditation/covid-19-guidance/ Accessed July 2020

4. Chang, H. What History Tells Us about the Distinct Nature of Chemistry. Ambix 2017, 64 (4), 360-374.

5. Snyder, R.; Dolan, J. W.; Lommen, D. C. Drylab ${ }^{\circledR}$ computer simulation for high-performance liquid chromatographic method development: I. Isocratic elution. J. Chromatogr. A 1989, 485, 65-89. 
6. Computer experiments. Some principles and examples. Craig, N. C.; Sherertz, D. D.; Carlton, T. S.; Ackermann, M. N. J. Chem. Educ. 1971, 48 (5), 310-313.

7. Wiegers, K. E.; Smith, S. G. J. Chem. Educ. 1980, 57 (6), 454-456.

8. Bourque, D. R.; Carlson, G. R. Hands-On versus Computer Simulation Methods in Chemistry. J. Chem. Educ. 1987, 64 (3), 232-234.

9. Blackburn, M. Improving Student Instrumentation Skills With Pre- and Postlab Computer Simulations. J. Chem. Educ. 199572 (6), 533.

10. Seery, M. K.; Agustian, H. Y.; Zhang, X. A Framework for Learning in the Chemistry Laboratory. Isr. J. Chem. 2019, 59, 546-553.

11. Clevenger, J. J. Chem. Educ. 1997, 74 (8), 894-895.

12. Laal, M.; Ghodsi, S. M. Benefits of collaborative learning. Procedia Soc. Behav. Sci. 2012, 31, 486-490.

13. A Community Springs to Action to Enable Virtual Laboratory Instruction, Nataro, C.; Johnson, A, R. J. Chem. Educ. 2020, https://doi.org/10.1021/acs.jchemed.0c00526

275 14. https://www/pogil.org, Accessed July 2020.

15. Richie, C. How to Collaborate Effectively. 2019 Education in Chemistry https://edu.rsc.org/ideas/how-to-collaborate-effectively/3010028.article (accessed Jun 2020)

16. Burke, K. A.; Greenbowe, T. J. Collaborative Distance Education: The Iowa Chemistry Education Alliance. J. Chem. Educ. 1998, 75 (10), 1308-1312.

17. Benatan, E.; Dene, J.; Stewart, J. L.; Eppley, H. J.; Watson, L. A.; Geselbracht, M. J.; Williams, B. S.; Reisner, B. A.; Jamieson E. R.; Johnson, A. R. JCE VIPEr: An Inorganic Teaching and Learning Community. J. Chem. Educ. 2009, 86 (6), 766-767.

18. a) Woo, D. T.; Hudson, B. T.; Mori, J. C.; Ngan, E. S. M.; Pak, W.-Y.; Haines R. S. Interdisciplinary Educational Collaborations: Chemistry and Computer Science, J. Chem. Educ. 2007, 84 (6), 967-970. b) Bevilacqua, V. L. H.; Powers, J. L.; Vogelien, D. L.; Rascati, R. J.; Hall, M.; Diehl, K.; Tran, C.; Jain, S. S.; Chabayta, R. Collaboration between Chemistry and Biology to Introduce Spectroscopy, Electrophoresis, and Molecular Biology as Tools for Biochemistry. J. Chem. Educ. 2002, 79 (11), 1311-1313. c) Wells, G.; Haaf, M. Investigating Art Objects through 
Collaborative Student Research Projects in an Undergraduate Chemistry and Art Course. J. Chem. Educ. 2013, 90 (12), 1616-1621. d) Huston, E. M.; Milligan, J. A.; Powell, J. R.; Smith, A. M.; Neal, D.; Duval, K. M.; DiNardo, M. A.; Stoddard, C.; Bell, P. A.; Berning, A. W.; Wipf, P.; Bandik G. C. Development of an Undergraduate Course in Chemical Laboratory Safety through an Academic/Industrial Collaboration. J. Chem. Educ. 2018, 95 (4), 577-583. e) Keller, H.; Cox, J. R. he Proteomics Stock Market Project. A Cross-Disciplinary Collaboration in Biochemistry and Business Education, J. Chem. Educ. 2004, 81 (4), 519-522.

19. a) Bozzelli, J.; Greenberg, A.; Levine, D. Research experiences for high school science groups: A model for collaboration between high schools and colleges. J. Chem. Educ. 1988, 65 (8), 705707. b) Snitynsky, R. B.; Rose, K.; Pegg, J. M. Partnering Teachers and Scientists: Translating Carbohydrate Research into Curriculum Resources for Secondary Science Classrooms J. Chem. Educ. 2019, 96 (4), 685-690. c) Frame, R.; Hennah, N.; Seery, M. When Teachers and Researchers Collaborate. Chemistry in Education, 2018, https://edu.rsc.org/ideas/whenteachers-and-researchers-collaborate/3008524.article (accessed Jun 2020).

20. Waugh, R. F. Creating a scale to measure motivation to achieve academically: Linking attitudes and behaviours using Rasch measurement. Br. J. Educ. Psychol. 2002, 72, 65-86.

21. Strayhorn, T. L. College Students' Sense of Belonging: A Key to Educational Success for All Students, 2nd Ed.; Routledge: New York, NY, 2018. https://doi.org/10.4324/9781315297293

22. Stadtfeld, C.; Voros, A.; Elmer, T.; Boda, Z.; Raabe, I. J. Integration in emerging social networks explains academic failure and success. Proc. Natl. Acad. Sci. U. S. A. 2019, 116 (3), 792-797.

23. McCabe J. M. Connecting in College: How Friendship Networks Matter for Academic and Social Success; University of Chicago Press, Chicago, 2016.

24. Schmidt, S. J. The importance of friendships for academic success. J. Food Sci. Educ. 2020, 19 (1), 2-5.

25. Turner, K. L. A framework to evaluate the transition to undergraduate studies in chemistry. In Teaching Chemistry in Higher Education: A Festschrift in Honour of Professor Tina Overton; Seery, M. K. and McDonnell, C., Eds.; Creathach Press, Dublin, 2019; pp. 9-22. 
26. Szteinberg, G.; Balicki, S.; Banks, G.; Clinchot, M.; Cullipher, S.; Huie, R.; Lambertz, J.; Lewis, R.; Ngai, C.; Weinrich, M.; Talanquer, V.; Sevian, H. Collaborative Professional Development in Chemistry Education Research: Bridging the Gap between Research and Practice. J. Chem. Educ. 2014, 91 (9), 1401-1408. 